\title{
Transition to Marine Ice Cliff Instability Controlled by Ice Thickness Gradients and Velocity
}



\begin{abstract}
Affiliations:
${ }^{1}$ Department of Climate and Space Science and Engineering, University of Michigan, Ann Arbor, MI, 48109.

${ }^{2}$ Department of Physics, University of Michigan, Ann Arbor, MI, 48109.

${ }^{3}$ School of Geography and Sustainable Development, University of St Andrews, St Andrews, UK, KY16 9AL

*Correspondence to: jbassis@umich.edu.
\end{abstract}

\begin{abstract}
:
Portions of ice sheets grounded deep beneath sea level can disintegrate if tall ice cliffs at the iceocean boundary start to collapse under their own weight. This process, called marine ice cliff instability, could lead to catastrophic retreat of sections of West Antarctica on decadal to century time scales. Here we use a model that resolves flow and failure of ice to show that dynamic thinning can slow or stabilize cliff retreat, but when ice thickness increases dramatically upstream from the ice cliff, there is a transition to catastrophic collapse. However, even if vulnerable locations like Thwaites Glacier start to collapse, small resistive forces from sea-ice and calved debris can slow down or arrest retreat, reducing the potential for sustained ice sheet collapse.
\end{abstract}

\section{One Sentence Summary:}

Disintegration of ice sheets is limited by how rapidly the ice can stretch and thin and how quickly icebergs float away.

\section{Main Text:}

The Antarctic and Greenland ice sheets are drained by glaciers and ice shelves that terminate in near vertical ice cliffs submerged in the ocean. The portions of these ice sheets grounded beneath sea level have the potential to catastrophically collapse through a spectrum of instabilities, including the marine ice sheet instability and the marine ice cliff instability (MICI) (1-4). MICI was only recently proposed and occurs because the height of ice cliffs is limited by the strength of ice (4). When glaciers retreat into an over-deepening basin-or ice shelf collapse 
exposes a tall ice cliff — cliffs become structurally unstable at a threshold cliff height, leading to runaway cliff failure and ice sheet disintegration $(3,4)$.

Because MICI proceeds through brittle failure, it could lead to rapid ice sheet mass loss, with serious implications for sea level rise in the 21st Century and beyond (3). Although there is evidence supporting the MICI in the paleo-record (5), MICI remains controversial because it has yet to be observed in modern day glaciers. Moreover, current models of MICI rely on quasiempirical parameterizations extrapolated from limited observations to simulate retreat $(3,6,7)$. Without understanding the processes that limit rates of collapse, projections of sea level rise remain uncertain.

Here we show that, contrary to the MICI hypothesis, ice cliffs perched just above the maximum cliff height will not always catastrophically collapse, even when grounded on retrograde bed slopes with ice thickness increasing upstream. Instead, we find that catastrophic collapse is triggered when the ice thickness gradient exceeds a critical threshold. To probe ice cliff stability, we use the m-ice model (8), which treats ice like a power-law viscous material only until a yield strength is reached $(9,10)$. Once the yield strength is reached, the ice deforms rapidly and accumulation of plastic strain in failed portions of the ice reduces the strength of ice, resulting in failure localization. Our m-ice simulations neglect transient elastic stresses. The starting point of our simulations thus roughly corresponds to the end point of the visco-elastic simulations in ref (11). Our simulations, however, use a representation of the strength of ice that is more appropriate for modern day Greenland calving glaciers and Antarctic ice shelves (8).

In our experiments, we first examined idealized slabs of ice on a flat bed with varying ice cliff thickness $(H)$ and water depth $(D)$, with ice thickness increasing upstream. For each simulation, the ice thickness or water depth was chosen empirically so that the stress at the ice cliff was initially perched slightly above the failure threshold. This resulted in simulations with an initially $135 \mathrm{~m}$ thick dry ice cliff, a $400 \mathrm{~m}$ thick glacier grounded in $290 \mathrm{~m}$ of water, and an $800 \mathrm{~m}$ thick glacier grounded in $690 \mathrm{~m}$ of water.

In the dry case ( $D=0, H \sim 135 \mathrm{~m}$, Fig. 1A-C), failure occurs as a slump. Calved debris accumulates ahead of the ice cliff, but the cliff is stable. After the initial slump, the glacier slowly thins and advances, with cascades of smaller calving events avalanching from the cliff top (Animation S1, Fig. 2A). The slope of the cliff is $\sim 55^{\circ}$, similar to observations of Eqip Sermia, Greenland, which has a $\sim 100 \mathrm{~m}$ tall cliff that terminates in tens of meters of water (12).

Moreover, additional simulations using a discrete element model to simulate brittle failure reveal similar patterns of failure, with a stable slumped cliff (Animations S5-S6), supporting the simplified continuum representation of failure used here.

We next simulated cliff collapse from a $400 \mathrm{~m}$ thick glacier terminating in $290 \mathrm{~m}$ of water (Fig. 1D-F, Animation S2), comparable to typical Greenland outlet glaciers. An initial full thickness fracture results in an iceberg that detaches. The berg is buoyant, drifts away and, unlike the dry 
case, does not provide a stabilizing compressive stress. The new calving face has a slight slope, resulting in buoyancy forces that trigger a second calving event. This exposes thicker ice upstream and causes another full thickness fracture, leading to a cycle of catastrophic cliff collapse (Fig. 2A, Animation S2). However, the addition of a small $\sim 25 \mathrm{kPa}$ back-stress at the ice cliff, similar to or smaller than the back-stress inferred in iceberg-choked Greenlandic fjords (13), slows retreat and prevents complete collapse (Fig. 2B). Retreat continues once the backstress or "buttressing" is removed. This is consistent with observations of Greenland glaciers that show the seasonal presence of sea-ice and icebergs clogging fjords stabilizes glacier retreat (1316).

Finally, we examined an $800 \mathrm{~m}$ tall cliff terminating in $690 \mathrm{~m}$ of water ( $25 \mathrm{~m}$ height-abovebuoyancy (Fig. 1 G-I), comparable to Greenland's largest outlet glaciers and to the current grounding line thickness of Thwaites and Pine Island glaciers. Here, calving initiates with a subaerial slump, which triggers a buoyant calving event (Fig. 1G, Animation S3). This is similar to the "footloose" theory of buoyant calving and observations of large Greenland glaciers (17-19). Thicker ice upstream is exposed as icebergs are quickly evacuated. However, episodic "serac" failure from the ice cliff results in a sequence of repeated events where wasting from the top of the ice cliff exposes a buoyant foot that episodically detaches (Fig. 1I). A small $25 \mathrm{kPa}$ backstress again stabilizes the ice cliff, this time resulting in cliff advance (Fig. 2C).

Our model predicts a distinct pattern of uplift near the ice cliff associated with progressive "serac" failure that precedes calving. This pattern of uplift is remarkably similar to observed patterns of uplift observed near the cliffs of thick Greenland glaciers (Fig. 3), although additional processes, like submarine melt and formation of a super-buoyant tongue, may also play a role in Greenland calving cliff evolution. Nonetheless, the agreement between observations and simulations hint that cliff failure may already be underway in sections of Greenland.

To determine if stable cliff positions are possible in the absence of buttressing, we varied upstream velocity and bed slope to assess stability of the $800 \mathrm{~m}$ cliff. We ran simulations for at least one year or until the glacier completely collapsed to determine mean rates of cliff advance (Fig. 4). Simulations were initialized with identical surface slopes. To examine the role of bed slope and ice thickness gradients in controlling cliff stability, we also performed a few simulations with half the initial surface slope, but equivalent ice thickness gradient (filled squares in Fig. 4).

For modest ice thickness gradients, we see patterns of retreat and advance largely controlled by the upstream velocity rather than the bed slope. Experiments performed with identical initial thickness gradients, but different bed slopes result in comparable rates of terminus advance/retreat. For modest ice thickness gradients, larger upstream velocities result in advancing cliffs, while smaller upstream velocities result in retreating cliffs. Glacier advance and retreat is separated by a transition region, where rates of terminus advance are small $(<100 \mathrm{~m} / \mathrm{a})$ and quasi-stable over our 1-2-year simulation period (Fig. S1). 
As the ice thickness gradient becomes increasingly negative-ice thickness increases upstream faster - there is an abrupt transition at a critical thickness gradient to catastrophic collapse for all inflow velocities (Fig. 4). This "marine ice cliff collapse" regime, is a consequence of the fact that retreat (by calving) exposes thicker ice upstream much faster than dynamic thinning can reduce the thickness of the upstream ice exposed. Glacier advance on a steeply sloping bed also increases cliff height, leading to runaway cliff failure and retreat rates exceeding tens of kilometers per year. This mechanism suggests that cliff stability is a strong function of dynamic thinning and hence, ice temperature. We confirmed this hypothesis with an additional set of simulations showing warmer ice stabilizes retreat and results in a larger magnitude (and flux dependent) critical thickness gradient (Fig. S2-S3).

Crucially, our results highlight the key role that dynamic thinning of the ice plays in controlling cliff failure. Resistance to collapse is controlled by a balance between upstream flux, dynamic thinning and advection of thicker ice from upstream (Supplementary Text). This results in two regimes of cliff collapse. In the first regime, dynamic thinning keeps pace with calving, preventing runaway collapse by restricting growth of the cliff height during retreat. This regime is characterized by uplift near the cliff that precedes calving and strongly resembles observed patterns of uplift in thick Greenland outlet glaciers (Fig. 3). The second regime, marine ice cliff collapse, occurs when ice thickness increases rapidly upstream. However, even if a glacier enters into a regime where marine ice cliff collapse is imminent, a relatively small back-stress on the ice cliff of a few tens of kilopascals can slow or even stabilize retreat, making sustained ice sheet collapse less likely. This back-stress can be provided by the mixture of icebergs, sea-ice and land-fast ice that abuts pinning points or ice margins. We also examined the possibility that gradual removal or weakening of an ice shelf could stabilize and prevent runaway retreat (11). Initializing simulations with $25-50 \mathrm{kPa}$ of buttressing and then ramping the buttressing down over 1-50 days (Fig. S4) shows that, consistent with our previous experiments, retreat and collapse can be postponed by a modest back-stress. The ice-cliff, however, remains precarious and retreat eventually accelerates, leading to collapse. These results support our previous interpretation, but further emphasizes that glacier geometry plays a dominant role in controlling rates of retreat associated with the marine ice cliff instability.

Thwaites Glacier, located in the Amundsen Sea Embayment of West Antarctica, is hypothesized to be one of the glaciers most vulnerable to cliff collapse (3). Our results suggest that disintegration or weakening of the floating ice shelf that currently buttresses Thwaites Glacier will expose a grounding line thickness large enough to initiate cliff retreat. At present grounding line conditions, Thwaites is unlikely to initially collapse. However, exposing the grounding line could trigger glacier retreat of a few kilometers per year (Fig. 3), comparable to the current retreat rate of large Greenland outlet glaciers like Jakobshavn Isbræ (Greenlandic: Sermeq Kujalleq) (20). Thwaites, however, is more than an order-of-magnitude wider than Jakobshavn and, even if Thwaites does not transition to catastrophic cliff collapse, initiating retreat would result in a substantial increase in the contribution of Thwaites Glacier to sea level rise. 


\section{References and Notes:}

1. J. Weertman, Stability of the junction of an ice sheet and an ice shelf. J Glaciol 13, 3-11 (1974).

2. J. H. Mercer, West Antarctic ice sheet and CO2 greenhouse effect: a threat of disaster. Nature 271, 321 (1978).

3. R. M. DeConto, D. Pollard, Contribution of Antarctica to past and future sea-level rise. Nature 531, 591-597 (2016).

4. J. N. Bassis, C. C. Walker, Upper and lower limits on the stability of calving glaciers from the yield strength envelope of ice. P Roy Soc a-Math Phy 468, 913-931 (2012).

5. M. G. Wise, J. A. Dowdeswell, M. Jakobsson, R. D. Larter, Evidence of marine ice-cliff instability in Pine Island Bay from iceberg-keel plough marks. Nature 550, 506-+ (2017).

6. T. L. Edwards et al., Revisiting Antarctic ice loss due to marine ice-cliff instability. Nature 566, 58-+ (2019).

7. T. Schlemm, A. Levermann, A simple stress-based cliff-calving law. Cryosphere 13, 2475-2488 (2019).

8. Materials and methods are available as supplementary materials at the Science website.

9. J. N. Bassis, L. Ultee, A Thin Film Viscoplastic Theory for Calving Glaciers: Toward a Bound on the Calving Rate of Glaciers. J Geophys Res-Earth 124, 2036-2055 (2019).

10. J. A. Olive, M. D. Behn, E. Mittelstaedt, G. Ito, B. Z. Klein, The role of elasticity in simulating long-term tectonic extension. Geophys J Int 205, 728-743 (2016).

11. F. Clerc, B. M. Minchew, M. D. Behn, Marine Ice Cliff Instability Mitigated by Slow Removal of Ice Shelves. Geophys Res Lett 46, 12108-12116 (2019).

12. A. Walter, M. P. Luthi, A. Vieli, Calving event size measurements and statistics of Eqip Sermia, Greenland, from terrestrial radar interferometry. Cryosphere 14, 1051-1066 (2020).

13. R. Cassotto, M. Fahnestock, J. M. Amundson, M. Truffer, I. Joughin, Seasonal and interannual variations in ice melange and its impact on terminus stability, Jakobshavn Isbrae, Greenland. J Glaciol 61, 76-88 (2015).

14. J. I. Walter et al., Oceanic mechanical forcing of a marine-terminating Greenland glacier. Ann Glaciol 53, 181-192 (2012).

15. J. C. Burton, J. M. Amundson, R. Cassotto, C. C. Kuo, M. Dennin, Quantifying flow and stress in ice melange, the world's largest granular material. P Natl Acad Sci USA 115, 5105-5110 (2018).

16. A. A. Robel, Thinning sea ice weakens buttressing force of iceberg melange and promotes calving. Nat Commun 8, (2017).

17. B. R. Parizek et al., Ice-cliff failure via retrogressive slumping. Geology 47, 449-452 (2019).

18. M. Trevers, A. J. Payne, S. L. Cornford, T. Moon, Buoyant forces promote tidewater glacier iceberg calving through large basal stress concentrations. Cryosphere 13, 18771887 (2019).

19. T. J. W. Wagner, T. D. James, T. Murray, D. Vella, On the role of buoyant flexure in glacier calving. Geophys Res Lett 43, 232-240 (2016).

20. E. M. McFadden, I. M. Howat, I. Joughin, B. Smith, Y. Ahn, Changes in the dynamics of marine terminating outlet glaciers in west Greenland (2000-2009). J Geophys Res-Earth 116, (2011). 
21. M. Alnæs et al., The FEniCS project version 1.5. Archive of Numerical Software 3, (2015).

22. C. Geuzaine, J.-F. Remacle, Gmsh: A 3-D finite element mesh generator with built-in pre- and post-processing facilities. International Journal for Numerical Methods in Engineering 79, 1309-1331 (2009).

23. J. M. Maljaars, C. N. Richardson, N. Sime, LEoPart: A particle library for FEniCS. Computers \& Mathematics with Applications, (2020).

24. D. Weatherley, ESyS-Particle v2. 0 user's guide. (2009).

25. Y. Wang, S. Abe, S. Latham, P. Mora, Implementation of Particle-scale Rotation in the 3D Lattice Solid Model. pure and applied geophysics 163, 1769-1785 (2006).

26. T. D. James, T. Murray, N. Selmes, K. Scharrer, M. O'Leary, Buoyant flexure and basal crevassing in dynamic mass loss at Helheim Glacier. Nat Geosci 7, 594-597 (2014).

27. D. I. Benn et al., Melt-under-cutting and buoyancy-driven calving from tidewater glaciers: new insights from discrete element and continuum model simulations. J Glaciol 63, 691-702 (2017).

Acknowledgments: Funding: We would like the thank the editor, Jesse Smith and 4 anonymous reviewers whose insight improved this manuscript. This work is from the DOMINOS project, a component of the International Thwaites Glacier Collaboration (ITGC). Support from National Science Foundation (NSF: Grant 1738896) and Natural Environment Research Council (NERC: Grant NE/S006605/1). Logistics provided by NSF-U.S. Antarctic Program and NERC-British Antarctic Survey. ITGC Contribution No. ITGC-044. Author contributions: JNB and BB wrote the m-ice model. JNB performed all simulations and data analysis. All authors contributed to planning experiments, interpreting results, writing and editing the manuscript. Competing interests: The authors declare no competing interests; Data and materials availability: The development version of the m-ice model is publicly available at https://github.com/jbassis/m-ice. The version of $\mathrm{m}$-ice used in this study along with all scripts used to generate figures is publicly available at https://github.com/jbassis/MICI-2021. 
Fig. 1. Snapshots showing the evolution of the ice cliff for different water depths and ice thicknesses. The color bar shows the effective strain rate $\epsilon_{I I}$. Dashed grey lines show the initial glacier geometry. Panels A-C show an initial slump for a dry calving cliff $135 \mathrm{~m}$ high. After the slump, the ice cliff stabilizes and advances. Panels D-F show a full thickness berg detaching from an ice cliff $400 \mathrm{~m}$ high, grounded in $290 \mathrm{~m}$ of water. The calving event exposes thicker ice upstream, triggering runaway failure and complete glacier disintegration. Panels G-I show snapshots from an ice cliff $800 \mathrm{~m}$ high, grounded in $690 \mathrm{~m}$ water depth. An initial slump triggers a buoyant calving event. Continued erosion of mass from the top of the cliff eventually triggers another buoyant calving event in a cyclical process. See Animations S1-S3. 
Fig. 2. Change in ice cliff position $(\Delta \mathrm{L})$ for the three ice thicknesses and water depth combinations shown in Fig. 1. Panel A shows initial retreat followed by advance of the $135 \mathrm{~m}$ thick glacier. The solid red lines in panels B-C show retreat of the cliff for the $400 \mathrm{~m}$ and $800 \mathrm{~m}$ thick glacier without buttressing. The dashed blue lines in Panels $\mathbf{B}$ and $\mathbf{C}$ show the stabilizing effect of $25 \mathrm{kPa}$ of buttressing. Buttressing was removed after day 90 (shown with a vertical gray line), triggering subsequent retreat (dashed red line). 
Fig. 3. Comparison between model snapshots (orange) and Operation IceBridge altimetry profiles (blue) over Jakobshavn Isbræ (Sermeq Kujalleq) and Helheim Glacier, Greenland. Panels A-B compares snapshots from simulations computed using a retrograde bed slope of 0.01 and upstream velocity of $6 \mathrm{~km} / \mathrm{a}$. Panel A shows a snapshot from a simulation with $25 \mathrm{kPa}$ of buttressing at the ice cliff, resulting in a flatter profile near the ice cliff. Panels C-D show snapshots computed using a flat bed and $4 \mathrm{~km} / \mathrm{a}$ upstream velocity. Models and observations in Panels B-D show significant uplift at the terminus that is especially pronounced for Helheim Glacier. 
Fig. 4. Average rate of terminus advance over one year for an initial $800 \mathrm{~m}$ thick glacier terminating in $690 \mathrm{~m}$ of water for a range of thickness gradients and upstream velocities. The bed slope is shown on the top axis. The filled squares are color coded to show the rate of terminus advance computed for half the initial surface slope. The approximate current thickness gradient and inflow velocity of the Thwaites Glacier grounding line is also marked, indicating retreat at a few kilometers per year, but not catastrophic collapse if the grounding line was exposed. 


\section{Supplementary Materials:}

Materials and Methods

Supplementary Text

Supplementary References (21-27)

Figures S1-S10

Movies S1-S5

Table S1-S2

Captions for Movies S1 to S5 


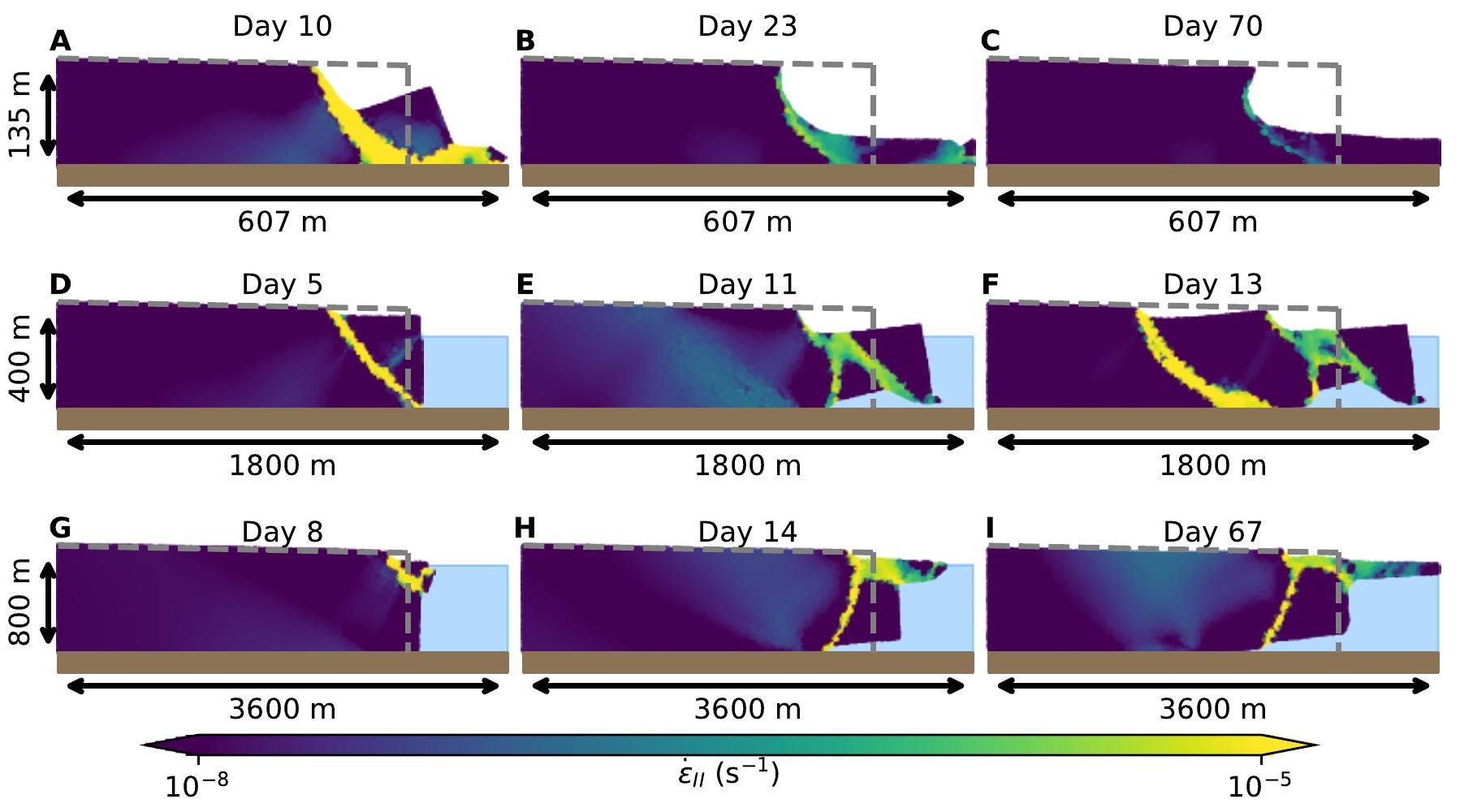




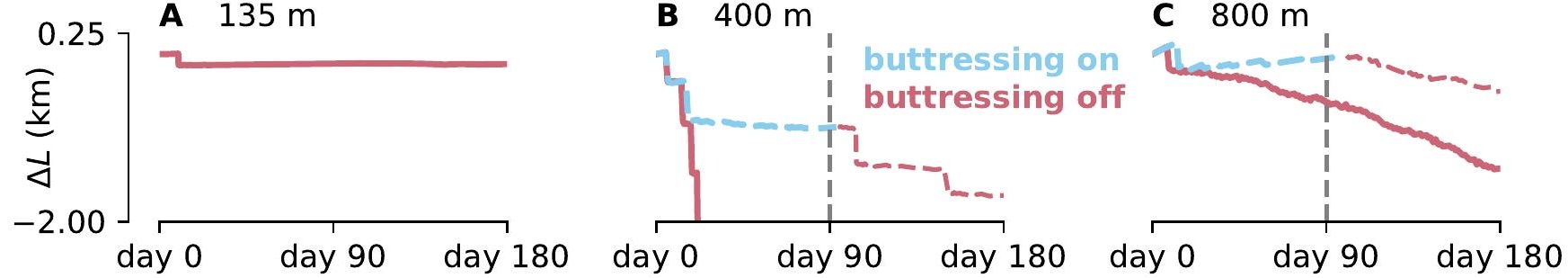



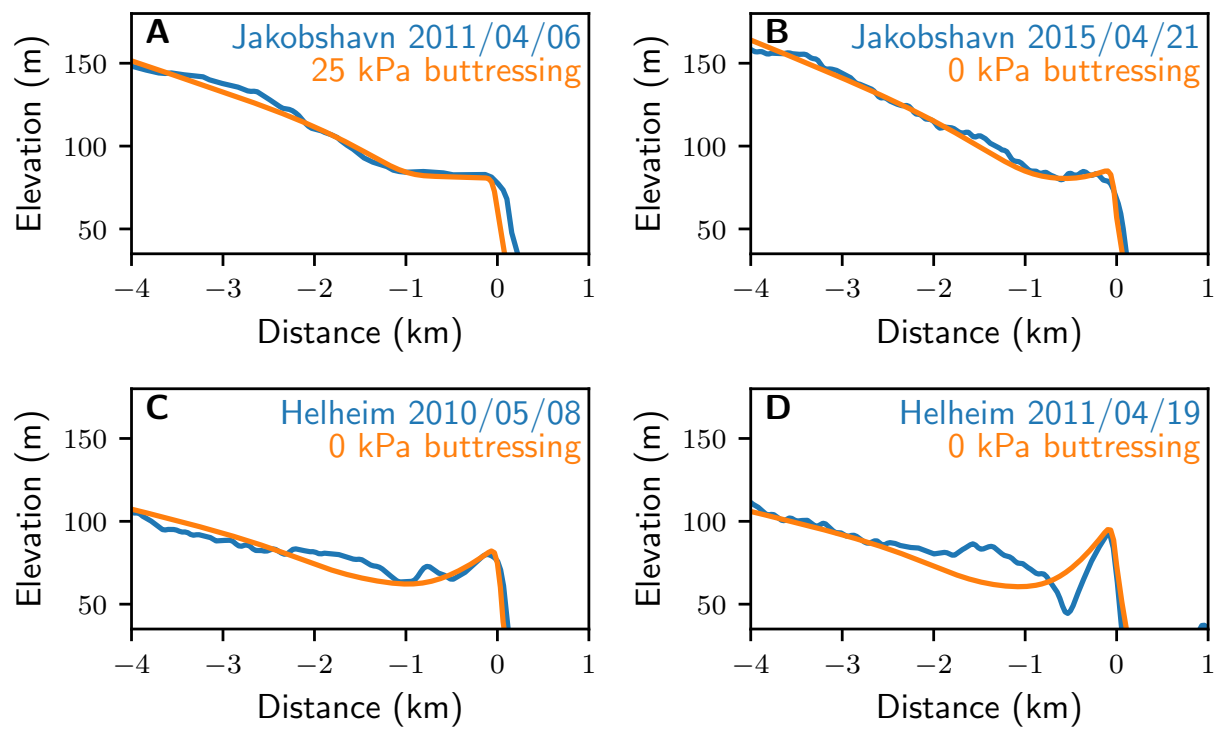
retrograde bed slope






\title{
Science МIAAAS
}

\section{Supplementary Materials for}

\section{Transition to Marine Ice Cliff Instability Controlled by Ice Thickness Gradients and Velocity}

\author{
Authors: J.N. Bassis' ${ }^{*}$, B. Berg1,2, A. Crawford ${ }^{3}$, D.I. Benn ${ }^{3}$ \\ Correspondence to: jbassis@umich.edu
}

This PDF file includes:

Materials and Methods

Supplementary Text

Supplementary References (21-27)

Figures S1-S10

Table S1-S2

Captions for Movies S1 to S5

Other Supplementary Materials for this manuscript include the following:

Movies S1 to S5 


\section{Materials and Methods}

We use two models in this study. The primary model we use, called m-ice, is a continuum model that treats ice as a viscous material that flows and fails. The $\mathrm{m}$-ice model treats ice as a viscous fluid, implicitly assuming elastic stresses are fully relaxed at all times. This loosely corresponds to the end-point in the visco-elastic simulations performed in ref (11). The second model we use is a discrete element model that treats ice as an elastic material consisting of boulders of ice glued together with breakable elastic bonds. The discrete element model is fully dynamic (i.e., acceleration is included in the force balance). The short-term elastic nature of the discrete element model is used to examine fracture patterns, but also corresponds to the short-elastic limit when a calving front is suddenly exposed prior to viscous relaxation and adjustment. We describe these two models in more detail below.

\subsection{The m-ice composite visco-plastic rheology}

The novelty of m-ice rests in how it uses a composite rheology that accounts for both flow and failure of ice, analogous to the treatment of semi-brittle failure in numerical models designed to simulate long-term geodynamic and lithospheric dynamics (see, e.g., ref 10). The model does not resolve individual fractures, but does account for multiple deformation processes that become more (or less) energetically efficient at different stress regimes, which we describe below.

1.1.1 Power law creep: Traditionally, glacier models assume ice follows a power-law rheology, called Glen's flow law, for all stresses. Denoting the effective viscosity of ice associated with power-law creep by $\eta_{d i s}$, the power-law creep component of the rheology can be written in the form:

$$
\text { (1) } \quad \eta_{\text {disl }}=\frac{B_{\text {disl }}}{2} \epsilon_{e}^{\frac{1}{n}-1} \text {, }
$$

where $\epsilon_{e}$ denotes the effective strain rate, $n=3$ is Glen's flow law exponent and $B_{\text {disl }}$ denotes the temperature dependent hardness of ice. The power-law creep relationship breaks down at both high and low stresses/strain rates. As the effective strain rate decreases, the viscosity increases and becomes singular for vanishing effective strain rates. Conversely, at high strain rates (or large stresses), ice eventually fails. Once ice has failed, the stress can no longer increase and often decreases with increasing load. We account for both of these modes of deformation in our continuum model.

1.1.2 Diffusion creep: At low effective strain rates, diffusion creep is thought to eventually become the dominant mode of deformation. Denoting the grain size by $d$, diffusion creep typically has the form:

$$
\text { (2) } \quad \eta_{\text {diff }}=\frac{B_{\text {diff }}}{2 d^{2}} \text {. }
$$

where $B_{\text {diff }}$ is a coefficient that depends inversely on temperature. In our simulations, diffusion creep is rarely energetically favorable, but is used instead as a physically based regularization for 
power-law creep at low strain rates. Our simulations use a grain size of 1-10 mm, but are insensitive to changing grain size or coefficient $B_{\text {diff }}$ across a wide spectrum of grain sizes and temperatures.

1.1.3 Semi-brittle failure at the yield strength: We follow refs. 8 and 9 and assume that once failure occurs, the effective stress can no longer increase with increasing strain rate. Denoting the yield strength of ice by $\tau_{y}$, we adopt a "plastic" failure rheology of the form (see, for example, ref 9 ):

(3) $\quad \eta_{\text {plas }}=\frac{\tau_{y}}{2 \epsilon_{e}}$.

Multiplying both sides of Equation (3) by the effective strain rate $\epsilon_{e}$, shows that the effective stress, $\tau_{e}$, is given by $\tau_{e}=2 \eta_{\text {plas }} \epsilon_{e}=\tau_{y}$ and the "plastic" rheology effectively caps the effective stress beneath the yield strength.

1.1.4 Composite rheology: We define a composite rheology by taking the harmonic average of the viscosities:

$$
\eta=\eta_{\min }+\left[\frac{1}{\eta_{\text {diff }}}+\frac{1}{\eta_{\text {disl }}}+\frac{1}{\eta_{\text {plas }}}\right]^{-1} .
$$

Here $\eta_{\min }$ represents a numerical minimum viscosity necessary for numerical convergence of the system of equations when ice has failed completely. In the harmonic average, the viscosity is a smooth, continuous and differentiable function of the effective strain rate. This composite rheology is illustrated in Fig. S5. Unlike the rheology proposed in ref (9), there is no abrupt transition to a yielded rheology at the yield strength. Instead, the ice begins to soften over a finite transition zone as the effective strain rate increases. This is numerically convenient, but is also realistic if there is a spectrum of pre-existing flaws that gradually become activated as the stress increases.

1.1.5 Ice strength decreases after reaching the yield strength: The final ingredient in our model is recognizing that once ice has reached the failure threshold, the effective stress typically decreases with increasing strain rate. We follow ref (10) and mimic this behavior by adopting a model where the yield strength of ice decreases linearly with the strain accumulated in yielded portions of the glacier. Denoting the intact strength by $\tau_{c}$ and plastic strain accumulated in faults and fractures by $\epsilon_{p}$, we assume the yield strength decreases with accumulated plastic strain according to:

$$
\tau_{y}=\max \left\{\tau_{c}-\left(\tau_{c}-\tau_{\text {min }}\right) \frac{\epsilon_{p}}{\epsilon_{c r i t}}, \tau_{\min }\right\} .
$$

Here $\tau_{\text {min }}$ denotes a minimum yield strength that accounts for the fact that ice maintains some strength after failure. We set this to be small enough that it makes little difference to our results with values typically of the range $10-25 \mathrm{kPa}$. For simplicity, we assume the rate of change of the plastic strain, $D \epsilon_{p} / D t$, increases proportional to the effective strain rate $\epsilon_{e}$ once the material 
reaches the yield strength. This model allows flow and failure of ice and, crucially, promotes localized failure, but is a caricature of the main modes of failure possible in actual ice. To assess how realistic the model is, we compare patterns of failure predicted by the model to a more rich (and computationally expensive) model that is capable of resolving fully brittle fracture (section $1.3)$.

1.1.6 Choice of yield strength: We initialized the yield strength to $0.75 \mathrm{MPa}$, which corresponds to a uni-axial tensile strength of $1.5 \mathrm{MPa}$. This value is within the range of observations (e.g., ref 4 , with a factor of 2 correction). Significantly decreasing the yield strength results in disintegration of Greenland sized glaciers. Increasing the yield strength results in completely intact glaciers for the glacier geometries considered here. Crudely, the yield strength can be related to the size of pre-existing starter flaws within the ice. For example, following ref (17) and denoting the critical stress intensity factor by $K_{I C}$ and crack halfwidth by $a$, a rough estimate of the strength of ice is $\tau_{y} \approx 2 K_{I C} / \sqrt{a}$. For $K_{I C} \sim 50-150 \mathrm{kPa} \mathrm{m}^{1 / 2}$, our estimate of the yield strength implies the presence of starter cracks that are tens of centimeters long. By contrast, ref (11) courageously assumes undamaged ice with only sub-centimeter starter flaws present. The assumption that ice is undamaged results in significantly stronger ice and a much larger inferred ice strength. It is this assumption that ice is undamaged with only grain sized starter flaws and not elastic stress relaxation that results in ref (11) predicting that cliffs are stable to a much greater height than obtained from our simulations. Our results are broadly consistent with starter flaw sizes appropriate for Greenland and Antarctic ice shelves inferred in ref (17). However, future work is needed to better establish the strength of ice and associated starter flaw size distribution, including how starter flaws evolves across a range of glaciological conditions to better constrain the strength of ice.

\subsubsection{Choice of sliding law}

For simplicity, we adopt a Weertman sliding law that, like the rheology of ice, is limited by the yield strength of ice. Denoting the traction along the bed by $\tau_{b}$ and the component of the glacier velocity tangent to the bed by $\mathbf{u}_{t}$, the composite sliding law takes the form:

$$
\tau_{b}=-\left\{\frac{1}{C\left|\mathbf{u}_{t}\right|^{1 / n-1}}+\frac{\left|\mathbf{u}_{t}\right|}{\tau_{c}}\right\}^{-1} \mathbf{u}_{t}
$$

where $C$ denotes the constant in the Weertman sliding law. Here, the sliding law is identical to the usual Weertman sliding law often used in ice sheet models, but softens as the yield strength of ice is approached.

\section{$\underline{1.2}$ The m-ice numerical implementation}

1.2.1 Finite element implementation and solver: We solved the momentum equations, incompressibility constraint along with equations (1)-(6) using the FENICS software (21). We used P1-P2 Taylor-Hood elements with linear elements for pressure and quadratic elements for velocity. We used a Picard iteration to solve the non-linear system of equations, iterating until 
the relative tolerance between successive guesses decreased to less than $10^{-6}$. The mesh was updated after each time step using the Arbitrary Lagrangian Eulerian (ALE) method built into the FENICS software suite using an Euler forward time step.

1.2.2. Initial condition and boundary conditions: For each glacier, we initialized our domain with a glacier with constant surface slope and bed slope. Glacier lengths for all glaciers were set to 12 times the initial thickness at the calving front to avoid contamination from the upstream boundary condition. The surface slope was set to -0.02 (negative because elevation increases upstream) for all simulations except a handful of simulations described in the text where the surface slope was set to -0.01 . The surface slopes are typical of outlet glaciers and for Thwaites and Pine Island glacier conditions near the grounding line. We applied a no-penetration boundary conditions on the grounded portions of glaciers, implemented with a penalty method, and buoyancy (normal traction) boundary conditions where the ice was floating. At the upstream edge of the domain, we specified the inflow velocity in the horizontal direction and used a freeslip (zero shear traction) boundary condition in the vertical direction to allow the glacier to thin and thicken at the upstream end. The ice thickness and water depth combinations where failure initiated were determined empirically by slowly increasing the ice thickness (for the dry cliff) or decreasing the water depth (for the $400 \mathrm{~m}$ and $800 \mathrm{~m}$ thick cliff) until the ice started to fail.

1.2.3 Meshing and remeshing: We meshed the initial domain into triangular elements using the meshing software Gmsh (22). Denoting the ice thickness at the calving front by $H$, we used roughly equal element sizes with characteristic length $H / 30$. This translates into roughly $\sim 30 \mathrm{~m}$ elements for $800 \mathrm{~m}$ thick glaciers, $\sim 15 \mathrm{~m}$ elements for $400 \mathrm{~m}$ thick glaciers and $\sim 5 \mathrm{~m}$ elements for $135 \mathrm{~m}$ thick glaciers. Because deformation is large, we remeshed the interior of the domain using Gmsh when element quality deteriorated. We used the FENICS built in function MeshQuality to quantify mesh deterioration, remeshing when the mesh quality deteriorated to less than 0.1 , roughly corresponding to elements elongated with a 10:1 aspect ratio. We also observed mesh tangling for a few experiments with large deformations that resulted in compressive stresses - e.g., some of the buttressing experiment. For these experiments the boundary of the glacier would intersect with itself resulting in an unphysical configuration. To avoid these cases, we remeshed manually when the mesh became tangled. Although this resulted in a smoothing of the mesh that did not preserve mass, mesh tangling only occurred in the calved debris and did not affect our simulations of failure of the glacier.

1.2.4 Strain memory and advection: To avoid artificial diffusion when advecting quantities, we introduced massless particles to serve as tracers and used the software package LEoPART (23) to advect and update quantities stored on particles. We used the finite element basis functions themselves to interpolate quantities from the mesh to the particles and vice versa. Because stress, viscosity and strain rates are not continuous between elements we used a DG1 (Linear Discontinuous Galerkin) element space for plastic strain $\epsilon_{p}$ when interpolating mesh properties to particles. To project from the particles to the mesh, we use a least squares procedure. For 
example, let $\phi_{p}\left(x_{p}, z_{p}\right)$ denote a scalar variable defined on the $p$ th particle, the projection from particles to the ith node on the mesh takes the form:

(7) $\phi_{i}=\frac{\sum_{p} \phi_{p} \xi_{i p}}{\sum_{p} \xi_{i p}}$,

where $\xi_{i p}$ denotes the shape function used in the ith element evaluated at the particle location $\left(x_{p}, z_{p}\right)$. This projection ensures that when $\phi_{p}$ is positive for all particles, the projection onto the mesh also remains positive. This procedure is identical to the usual material point method (MPM) of projection for particles with unit mass, but we do not use particles as integration points in the domain. We used LEoPART functionality AddDelete to add and removed particles to ensure that at we always had at least 8 particles per element and no more than 16 particles per element.

1.2.5 Time stepping and numerical convergence: We used an Euler forward time step to update the mesh and particle properties, but a 3rd order Runge-Kutta scheme to update particle positions, using the smaller of a 3 hour time step or the CFL criterion. We also conducted numerical convergence studies using both larger and smaller spatial resolutions and time step sizes. Decreasing the time step or mesh size by half only made a small difference to the timing of the initial calving event, indicating that solutions are close to being numerically converged and made no difference to our uni-axial compression experiments. However, because of the nonlinearities in the system of equations, small changes in the initial condition eventually result in large differences in the simulation results for times that are long compared to a single calving event. As in nature, the timing of simulated calving events becomes increasingly difficult to predict far into the future. However, this sensitive dependence to initial conditions makes little difference to the mean terminus position or mean rate of retreat when averaged over multiple calving events; quantitative patterns under different glaciological conditions remain robust under grid refinement and when using different time stepping schemes and time step sizes. The exception is in a small parameter region near the critical ice thickness, where a bifurcation occurs and small differences in the initial condition can push an otherwise stable glacier into the catastrophic collapse regime. This introduces a small uncertainty into the critical ice thickness gradient. We minimized this uncertainty by running simulations that disintegrated multiple times to make sure results were consistent between multiple simulations.

1.2.6 Surface mass balance: We did not include surface mass balance because melt rates up to a few meters per year had a negligible affect on simulations over the 1-2 years of simulation time performed.

\section{$\underline{1.3 \text { Model calibration and comparison with a discrete element model }}$}

The composite rheology we use represents a simplification of the full spectrum of brittle and semi-brittle failure processes. To assess how well our simplified continuum representation of flow and failure compares to a more complete specification of brittle fracture, we performed an 
additional set of simulations using a discrete element model (DEM). The goal of these simulations was to assess the qualitative behavior of the $\mathrm{m}$-ice model and determine if fracture patterns we obtained are realistic. To simulate brittle failure, we used the open source Esysparticle model, a discrete element model (DEM) that simulates aggregates of spheres (in 3D) or disks (in 2D) that are bonded together using elastic breakable bonds (24). Fully specifying elastic-brittle behavior in a three-dimensional discrete element model requires 4 independent elastic parameters along with 4 independent fracture thresholds. These degrees of freedom correspond to (1) motion normal to bonds, (2) shearing of bonds, (3) bending of bonds and (4) torsion of bonds (25). Our simulations, are restricted to two-dimensions and eliminate torsion, leaving 6 independent parameters. To parameterize fracture, we use the "BrittleBonds" representation of failure in Esys-particle, which represents bonds as cylindrical beams subject to the Mohr-Coulomb failure criterion. This reduces the number of elastic bond parameters to two (Young's modulus and Poisson's ratio for bonds). Brittle failure of bonds requires specification of the shear strength (cohesion) $\tau_{c}$, and coefficient of friction $\mu$. The tensile strength is given by $\alpha \tau_{c} / \mu$, where $\alpha$ is a cutoff parameter that corresponds to the fact that most materials are weak in tension. We set $\alpha=0.1$ for simulations. The macroscopic elastic and brittle properties, however, depend on both bond properties and packing geometry. Hence, we need to first calibrate the DEM to determine the effective macroscopic parameters elastic and fracture parameters.

1.3.1 Uni-axial compression calibration. In our first experiment, we performed a uni-axial compression experiment to calibrate the DEM (Fig. S6). For the DEM model, we gradually increased strain quasi-statically using a sample size of $10 \mathrm{~cm}$ by $10 \mathrm{~cm}$. We then performed two simulations with the DEM using different parameters (summarized in Table S2). The first, called DEM1, set the bond shear strength to $0.02 \mathrm{MPa}$, while the second, called DEM2, doubled the bond shear strength to $0.04 \mathrm{MPa}$. These bond strengths correspond to a peak uniaxial compressive strength of 1.5 MPa and 3 MPa, respectively (Fig. S6). The calibrated Young's modulus was determined for both simulations by fitting a straight line to the linear elastic loading portion of the stress/strain curve resulting in a Young's modulus of $~ 5 \mathrm{GPa}$. For reference, we also show a similar uni-axial compressive test computed for $\mathrm{m}$-ice using a gradual increase in strain rate. Comparing failure behavior of the DEM simulations with $m$-ice, we see the initial stage of stress increase is elastic for the DEM, whereas it is viscous for $m$-ice. Despite this difference, the DEM and m-ice models exhibit similar patterns of increasing stress until failure is reached, followed by a more rapid decrease in stress as strain becomes localized in fractures.

1.3.2 Calibration of yield strength for dry calving front failure. To compare patterns of failure under glaciological relevant loading conditions, we next examined purely brittle failure of a dry (zero water depth) calving front, analogous to Fig 1 A-C, using the DEM model calibrated in the previous section. Animation $\mathbf{S} \mathbf{4}$ shows an example simulation computed with parameters from DEM1 with a $70 \mathrm{~m}$ ice cliff thickness. The pattern of failure seen in the simulation is analogous to that seen in $\mathrm{m}$-ice, with an initial slump that stabilizes. Decreasing the calving front thickness to $50 \mathrm{~m}$ results in a stable cliff that does not fail. Although the pattern of failure is similar to $\mathrm{m}$ - 
ice, the ice fracture parameters in the brittle model results in a glacier that is weaker and more fragile. This is partly a consequence of the fact that we initialized the DEM from rest and this resulted in a "shock" as elastic bonds initially strained (and broke) under the action of gravity. Not surprisingly, ice is much more fragile under the dynamic loading inherent in the discrete element model than in the quasi-static loading assumed by $\mathrm{m}$-ice. For comparison, Animation S5, shows a simulation with a $135 \mathrm{~m}$ tall cliff and twice the shear strength, corresponding to parameters from DEM2. As anticipated, the maximum stable ice thickness scales with ice strength. These results indicate that $\mathrm{m}$-ice results reproduces qualitatively fracture patterns observed in the DEM, but the corresponding brittle fracture parameters may be much higher under dynamic loading than expected from quasi-static simulations compounding uncertainty in estimating ice strength from laboratory or field measurements under different loading conditions.

\subsection{Parameter sensitivity.}

1.4.1 Sensitivity to bed friction. For simplicity, we held the sliding law and all sliding law coefficients constant for all experiments to better isolate the effects of geometry, inflow velocity and ice temperature. Our results, however, are qualitatively similar for different sliding laws. For example, Fig. $\mathbf{S 7}$ shows the effect of tripling the friction coefficient on the evolution of terminus position. Here, the larger sliding law coefficient results in a larger surface slope (and larger ice thickness gradient), which then increases the retreat rate. This suggest that sliding law parameters could alter the critical thickness gradient at which catastrophic collapse occurs, but the overall pattern we show will remain the same.

\subsubsection{Sensitivity to failure parameters. In addition to bed friction, the primary physical} parameters that control model behavior are (1) the yield strength, (2) the critical strain rate, (3) the minimum viscosity and (4) the minimum yield strength. Our results are primarily sensitive to the yield strength and critical strain rate with the minimum viscosity and minimum yield strength playing a much smaller role. For example, decreasing the minimum viscosity by an order of magnitude accelerates the calving time scale by about a factor of two. Decreasing the minimum yield strength had no effect on our simulations. The parameters that have the greatest effect are the yield strength and critical strain rate. Increasing or decreasing the yield strength results in a linear change in critical ice thickness when calving cliff collapse is initiated, but all of our results scale linearly. Decreasing the critical strain, accelerates failure and results in a more rapid sequence of calving events. So long as the dynamic thinning of ice is increased proportionally (by increasing the ice temperature), this has no effect on our results. However, for a given ice temperature, accelerating failure makes the ice less stable. If the critical strain is decreased significantly below 0.1 , any calving event results in catastrophic failure of the ice for all surface slopes and bed slopes. When set to around 0.1 , calving events occur roughly every month, which is not that dissimilar to the pacing of large calving events in Greenland, although calving events can be more frequent in the summer and less frequent in the winter. Crucially, the qualitative pattern of our results remains robust to parameter changes. 
1.4.3 Stabilizing effect of a small back-stress from mélange:_ Once retreat is initiated, rapid discharge of icebergs could form a collection of icebergs weakly constrained by lateral geometry or pinning points in pro-glacial embayment. To examine the effect of buttressing, we applied a constant traction on the seaward side of the glacier in the horizontal direction using a contact area that extended from $25 \mathrm{~m}$ above sea level to $55 \mathrm{~m}$ beneath sea level (illustrated in Fig S8, panel A). Extending or reducing the contact area beneath sea level did not alter the results, but significantly shrinking the contact area above sea level reduced the effectiveness of the buttressing.

1.4.4 Sensitivity to slow removal of buttressing: We also examined the possibility that slower removal of buttressing associated with weakening of a semi-intact ice shelf could allow the glacier to dynamically adjust and stabilize, preventing catastrophic collapse. For example, ref (11) argued that ice shelf weakening over weeks to months proceeding final collapse may be important in relaxing transient elastic stresses. Our simulations start with elastic stresses fully relaxed, and thus our initial conditions are analogous to the final "slow shelf removal" conditions advocated for by ref (11). However, to assess the extent to which our results depend on the specific idealized geometry we used and to determine if gradual removal of buttressing could alter our results, we performed an addition suite of simulations where we relaxed an initial backstress over 1, 10 and 50 days. Following ref (11), we gradually decreased the magnitude of buttressing and vertical extent over which buttressing was applied to mimic slow removal of an "ice shelf" over time interval $\Delta t$ (illustrated in Fig. S8, panel B).

Removing $25 \mathrm{kPa}$ of buttressing over a single day (compare panels A and B in Fig. S4), had little effect on our simulations. Somewhat surprisingly, removing buttressing over 10 days appears to accelerate disintegration. This is a consequence of the fact that the buttressing only postpones the initial calving event slightly, but the back-force results in slightly thicker ice upstream because it slightly reduces dynamic thinning prior to the calving event. Subsequent failure exposes thicker ice, ultimately accelerating glacier collapse once retreat initiates. Reducing buttressing over 50 days can postpone collapse, but collapse still eventually occurs. Intriguingly, the smaller $25 \mathrm{kPa}$ back-stress postpones collapse longer than the $50 \mathrm{kPa}$ back-stress. This is likely because the $25 \mathrm{kPa}$ buttressing is able to postpone failure, but only has a modest effect on dynamic thinning over the 50 day ramp-down period. The larger $50 \mathrm{kPa}$ back-stress plays a more significant role in reducing dynamic thinning leaving the glacier more vulnerable to runaway retreat at the onset of failure. These results all support our previous interpretation, but further emphasize that glacier geometry - and all of the factors that control how this geometry evolves prior to the onset of retreat - play a dominant role in controlling rates of retreat associated with the marine ice cliff instability. 


\subsubsection{Effect of hydrodynamics:}

Both models that we used in simulating fracture and failure of ice assume the ocean can be approximated as a hydrostatic pressure that acts on the ice. This is reasonable over the long time scales that we focus on here, but neglects shorter-term hydrodynamic effects including waves, tsunamis and a host of other phenomena that could be important over the time scale of individual berg detachment. However, the role of hydrodynamics is likely to increase the stresses acting at the calving face and render our model conservative in estimating when fracture and failure initiate.

\subsubsection{Effect of complex bed topography}

Our experiments used an idealized bed characterized by a linear slope. This is a valid approximation near the terminus of many glaciers that slope gently inland. However, for more complex bed geometry we anticipate the critical ice thicknesses - and bed slopes - would need to be averaged over an interval comparable to or larger than ice thickness. Moreover, our simulations do not include transverse to flow variability in bed topography. Large transverse to flow variability over the width of a glacier could also play a role in promoting or stabilizing glaciers, although this may depend on subtle details of the specific bed topography. Nonetheless, we expect our results to remain approximately qualitatively valid when bed topography is averaged over the width of the glacier, but strong lateral bed variability would need to be more systematically explored, especially in narrow glaciers where lateral resistance to flow from the glacier margins becomes significant.

\section{Supplementary Text:}

\subsection{Conceptual model of catastrophic cliff failure}

One of our main results in the manuscript is that catastrophic cliff retreat can be trigged when the ice thickness gradient exceeds a critical threshold. We show here that this can be explained using a simple conceptual model. The basis of the mechanism we propose is that both advance and retreat increase the height of the calving cliff above sea level resulting in runaway cliff failure for any upstream velocity. Denoting the cliff height relative to sea-level by $h$, we can write an equation for the approximate evolution of glacier cliff height at the calving front, assuming the cliff remains grounded:

$$
\frac{D h}{D t} \approx u \frac{d b}{d x}-u_{c} \frac{\partial h}{\partial x}-\frac{\partial u}{\partial x}(h-b) .
$$

Here $D / D t$ denotes the advective derivative of cliff height (i.e., following the cliff), $b(x)$ denotes the bottom of the glacier, $u(x, t)$ denotes the depth averaged terminus velocity and $u_{c}(t)$ denotes an approximate time averaged "calving speed". All quantities are evaluated at the calving front. 
Equation (7) only holds as a depth averaged approximation and we have neglected surface mass balance, consistent with our model implementation (and the fact that surface mass balance is typically small compared to the other terms in Equation 7).

The first term on the right hand side of Equation (7) represents the rate of increase in cliff height as the glacier advances over a sloped bed. This term is positive when the bed slope is retrograde (positive $d b / d x$ ) and increases with the magnitude of the velocity and bed slope. Because the surface elevation increases upstream (negative $\partial s / \partial x$ ), the second term in Equation (7) represents the increased cliff height associated with glacier retreat (by calving) into a region of thicker ice. Finally, the third term on the right hand side represents dynamic thinning at the calving front and acts to reduce the cliff height $h$.

Defining the ice thickness $H=h-b$, we can rearrange Equation (7) to show:

$$
\frac{D h}{D t} \approx-\left(u+u_{c}\right) \frac{\partial H}{\partial x}-\frac{\partial u}{\partial x} H+u \frac{\partial s}{\partial x}-u_{c} \frac{d b}{d x} .
$$

Recalling that the ice thickness gradient $\partial H / \partial x$ is negative when ice thickness increases upstream, the first term in Equation (8) is typically positive and results in an increased cliff height. In many cases we examined, the first two terms in Equation (8) are the largest on the right hand side, resulting in a competition between advection of thicker ice to the terminus (by flow and failure) and dynamic thinning at the calving front. The thinning and calving rates are both largely controlled by the ice thickness, water depth and ice temperature and hence the balance between advective thickening and dynamic thinning is primarily controlled by the thickness gradient, but with a strong temperature dependence. This is the origin of the critical thickness gradient observed in our simulations.

More generally, for a retrograde bed, the first term in Equation (7) represents the increase in cliff height associated with glacier advance over a retrograde bed. This term is positive and works to further increase the cliff height, strengthening the instability. For large glacier velocities (or very steep beds), this term can, initially at least, dominate, leading to catastrophic collapse at lower critical thicknesses. For example, we observed catastrophic disintegration in simulations with a bed slope of 0.01 and upstream velocity of $12 \mathrm{~km} / \mathrm{a}$. As a consequence, we anticipate that fully characterizing catastrophic cliff collapse across a wide range of glaciological regimes will involve both the ice thickness gradient and the bed slope.

Our analysis, however, neglects the potentially complex role of submarine melting along the terminus. Submarine melting could either increase or decrease the instability, depending on how melting is distributed vertically across the calving face. Although we are reasonably confident in the patterns of calving simulated in this study, the largest uncertainty in our model rests in quantifying the calving speed $u_{c}$ and how this varies as a function of cliff height $h$. Despite this uncertainty, the broad pattern we sketched out here will still apply if $u_{c}$ increases or decreases. The primary difference is this will alter the critical thickness gradient estimated. 


\subsection{Limits of the m-ice model in resolving buoyant calving}

Fig. 3 shows that our simulations predict uplift with magnitude and wavelength comparable to that observed in thick Greenland glaciers, like Helheim and Jakobshavn glaciers. This match between observations and simulations occurs without any model tuning. Moreover, we obtain similar patterns of uplift on both prograde and retrograde beds indicating that this mode of cliff uplift is insensitive to bed geometry. However, m-ice cannot resolve fractures or closely spaced seracs. As a consequence, buoyant failure associated with erosion of ice from the cliff top cannot be fully separated from an analogous mode of failure where densely space seracs - or seracs toppling over — result in a buoyancy force that triggers calving as sketched out in Fig. S9.

\subsection{Basal crevasses and super buoyant calving}

An alternative model for buoyant calving of Greenland glaciers suggests that flexure associated with glaciers advancing on a steeply sloping prograde bed is the primary driver of calving (26, 27). In this model, the cliff top is assumed to be intact and largely serac free with calving progressing through the formation of basal crevasses. To asses this mode of failure, we performed a set of simulations without failure, allowing glaciers to advance on prograde beds, but these simulations, like the ones in ref (27) do not generate cliff uplift, much less calving front uplift of the magnitude observed near Helheim.

To generate calving cliff uplift, we had to manually introduce a basal crevasse into the initial mesh and increase the water depth to near super-buoyant levels. In these simulations, rotation of the submerged ice associated with basal crevasse eventually leads to a full thickness calving event, with large depressions formed at the surface above the basal crevasse and large uplift at the calving front (Fig. S10). However, increasing the ice thickness or decreasing the water depth results in large compressive stresses at depth that prevent basal crevasses propagation resulting in a transition to the ice cliff failure regime previously found. Given observations of slumping in Helheim Glacier (17), this suggests that the current cliff failure regime may consist of an interplay between both basal crevasse dominated failure and slumping buoyant failure. Nonetheless, as the height-above-buoyancy or cliff height increases, we anticipate the slumping or "serac" failure to increasingly dominate. 


\section{Supplementary References}

21. M. Alnæs et al., The FEniCS project version 1.5. Archive of Numerical Software 3, (2015).

22. C. Geuzaine, J.-F. Remacle, Gmsh: A 3-D finite element mesh generator with built-in preand post-processing facilities. International Journal for Numerical Methods in Engineering 79, 1309-1331 (2009).

23. J. M. Maljaars, C. N. Richardson, N. Sime, LEoPart: A particle library for FEniCS. Computers \& Mathematics with Applications, (2020).

24. D. Weatherley, ESyS-Particle v2. 0 user's guide. (2009).

25. Y. Wang, S. Abe, S. Latham, P. Mora, Implementation of Particle-scale Rotation in the 3D Lattice Solid Model. pure and applied geophysics 163, 1769-1785 (2006).

26. T. D. James, T. Murray, N. Selmes, K. Scharrer, M. O'Leary, Buoyant flexure and basal crevassing in dynamic mass loss at Helheim Glacier. Nat Geosci 7, 594-597 (2014).

27. D. I. Benn et al., Melt-under-cutting and buoyancy-driven calving from tidewater glaciers: new insights from discrete element and continuum model simulations. J Glaciol 63, 691-702 (2017). 


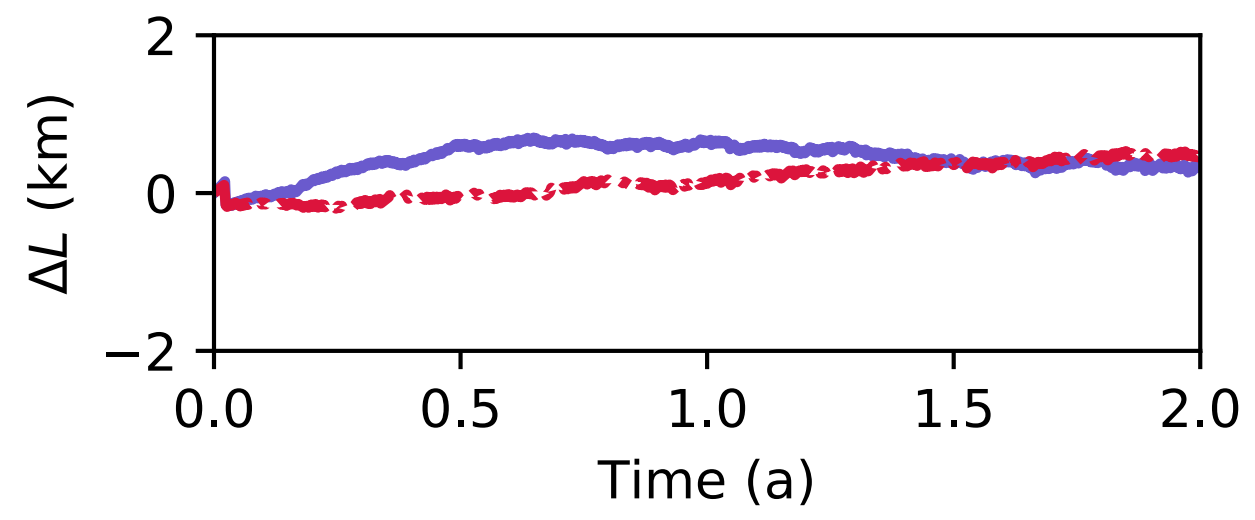

Fig. S1. Change in terminus position over two years for two $800 \mathrm{~m}$ thick glaciers initially grounded $25 \mathrm{~m}$ above buoyancy with identical initial thickness gradients and a $4 \mathrm{~km} / \mathrm{a}$ upstream velocity. The solid blue line shows an example with a bed slope set to 0.01 and initial surface slope of -0.02 , while the dashed red line shows an example with a bed slope set to 0.02 and initial surface slope of -0.01. Despite the difference in bed slopes, the terminus position for both of these glaciers remain close to the initial terminus position with little longterm advance or retreat. The surface slope, however, evolves over the two years of the simulation. 




Fig. S2. Effect of temperature on rate of advance $\Delta L$ of an $800 \mathrm{~m}$ thick calving front with a bed slope of -0.02 and $3 \mathrm{~km} / \mathrm{a}$ upstream velocity for three different ice temperatures. Although warmer ice temperatures result in a shorter time to the initial calving event, we see catastrophic disintegration for the coldest ice, while warmer ice temperatures result in a stable or advancing calving front position. 




Fig. S3. Effect of temperature on the critical thickness gradient. For cold, $-20^{\circ} \mathrm{C}$ ice, the critical thickness gradient is nearly constant for all upstream velocities. As the ice temperature warms, the critical thickness gradient where catastrophic collapse occurs becomes more negative (ice thickness increases faster upstream from the calving cliff) and exhibits an upstream flux dependence. 

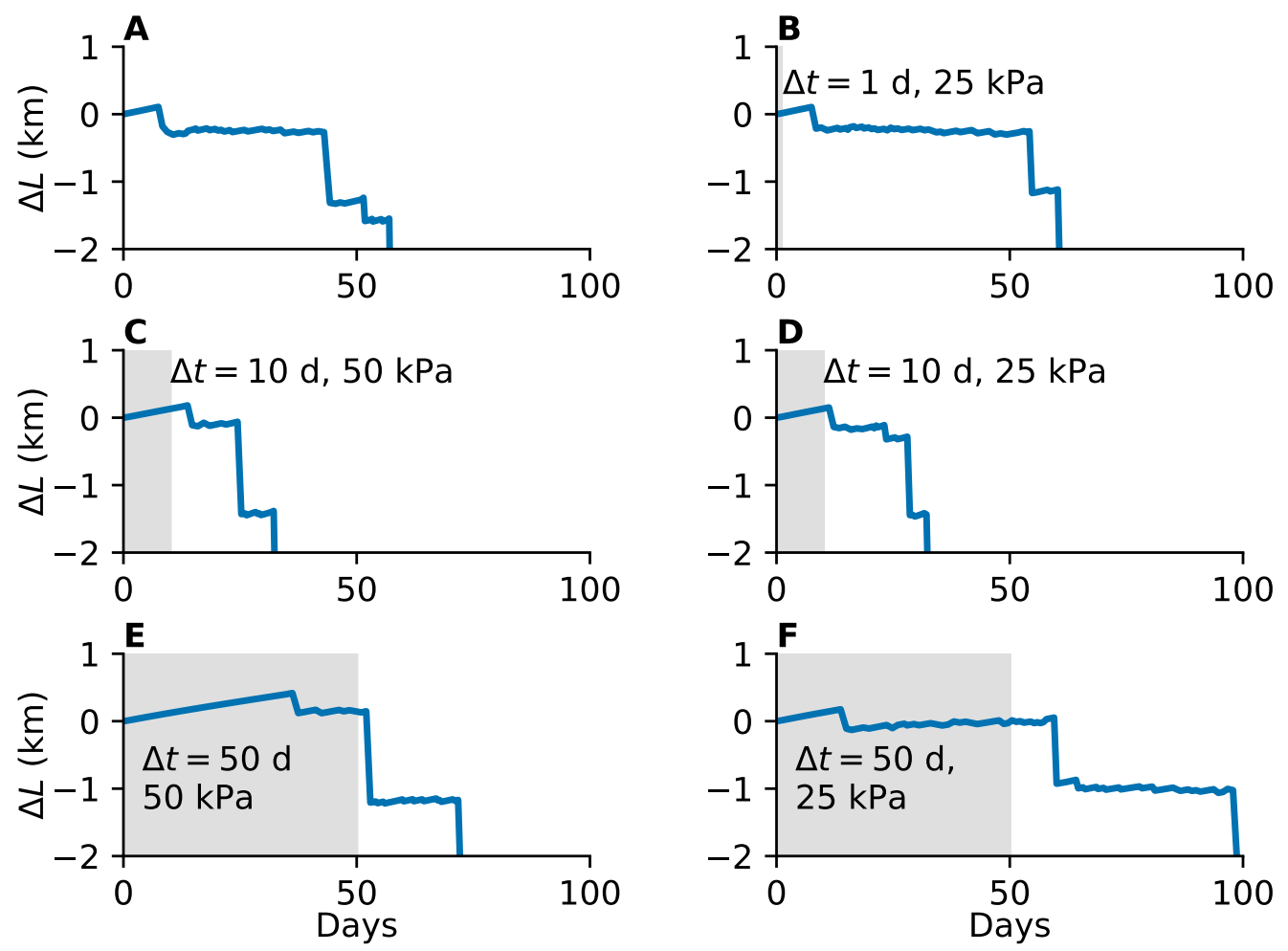

Fig. S4. Effect of gradually removing buttressing from an unstable glacier configuration for an $800 \mathrm{~m}$ thick calving front. The retrograde bed slope was set to 0.02 and surface slope -0.02 with a $2 \mathrm{~km}$ upstream in flow velocity. Shaded gray boxes indicate the interval of time where buttressing was linearly ramped down. Panel A shows the baseline simulation with buttressing instantaneously removed. Panel B shows the effect of removing $50 \mathrm{kPa}$ of buttressing removed over $\Delta t=1$ day. Panels C-D illustrate the effect of removing $50 \mathrm{kPa}$ and $25 \mathrm{kPa}$ of buttressing over $\Delta t=10$ day. Panels E-F show $50 \mathrm{kPa}$ and $25 \mathrm{kPa}$ of buttressing removed over $\Delta t=50$ days. Although buttressing can slow or postpone disintegration, all cases eventually collapse. 

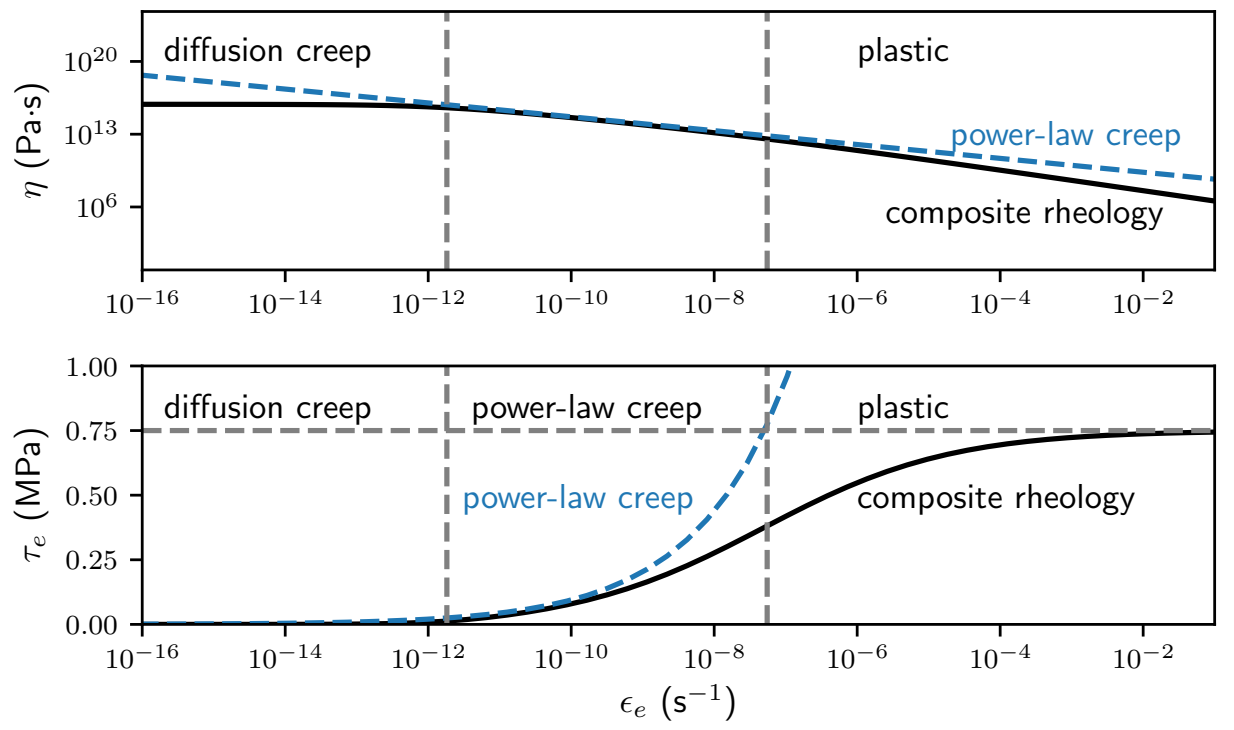

Fig. S5. Diagram showing the effective viscosity (top panel) and effective stress (bottom panel) for the composite rheology used by $\mathrm{m}$-ice for an ice temperature of $-20^{\circ} \mathrm{C}$ and yield strength set to $0.75 \mathrm{MPa}$. The blue dashed line shows a pure dislocation creep rheology for reference. The three creep regimes associated with the composite creep law are denoted by vertical dashed gray lines. The diffusion creep regime dominates at low strain rates, where the effective viscosity is nearly constant. At intermediate strain rates - typical of glaciers and ice sheets - power-law creep with $\mathrm{n}=3$ becomes the dominant deformation mechanism. Above a temperature dependent critical strain rate, the ice becomes yielded and "plastic" flow dominates. In our model, plastic strain $\epsilon_{p}$ only accumulates in the yielded regime. 




Fig. S6. Comparison between uni-axial compressive failure in a discrete element model and $\mathrm{m}$ ice. Parameters for DEM1 and DEM2 are summarized in Table S2. Simulations with the discrete element model were performed by gradually increasing the strain (bottom axis) whereas those done with m-ice where done by gradually increasing the strain rate (top axis). Both models show the same pattern of increasing stress until the failure threshold is reached, after which the stress abruptly decreases, but does not go to zero. 


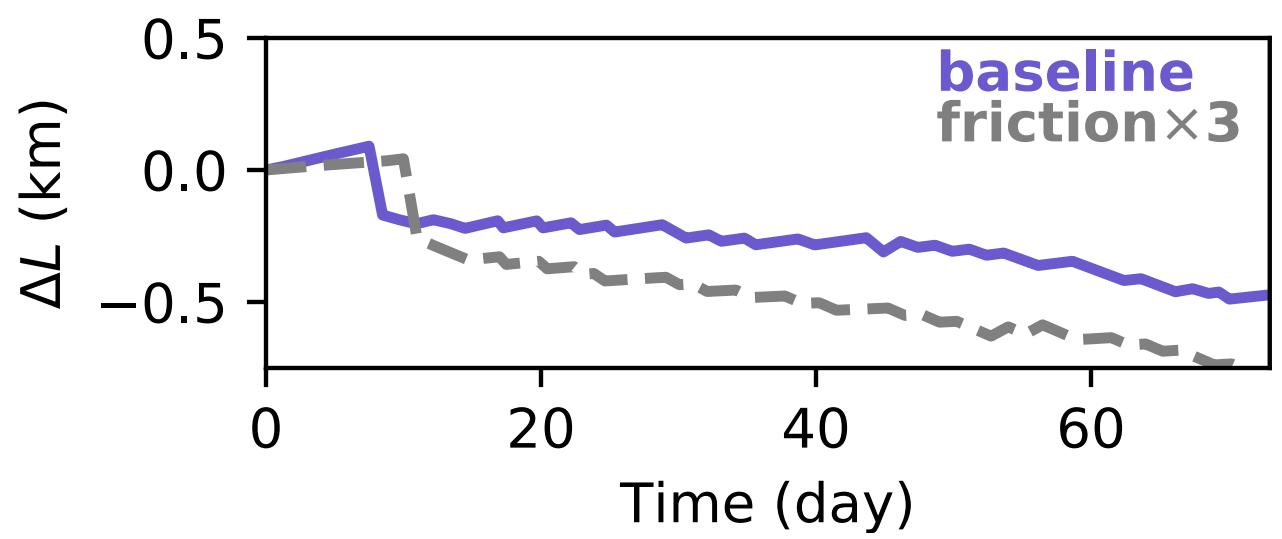

Fig. S7. Effect of friction coefficient on terminus position, $\Delta L$, of an $800 \mathrm{~m}$ thick calving front with zero bed slope and zero upstream velocity. The blue line shows the baseline friction coefficient (Table S1). The dashed gray line shows an analogous simulation with friction coefficient three times larger. We see a similar pattern of retreat, but the retreat rate for the larger sliding coefficient is slightly faster because the higher bed friction results in a larger surface slope and larger ice thickness gradient. 
A. Buttressing from icebergs

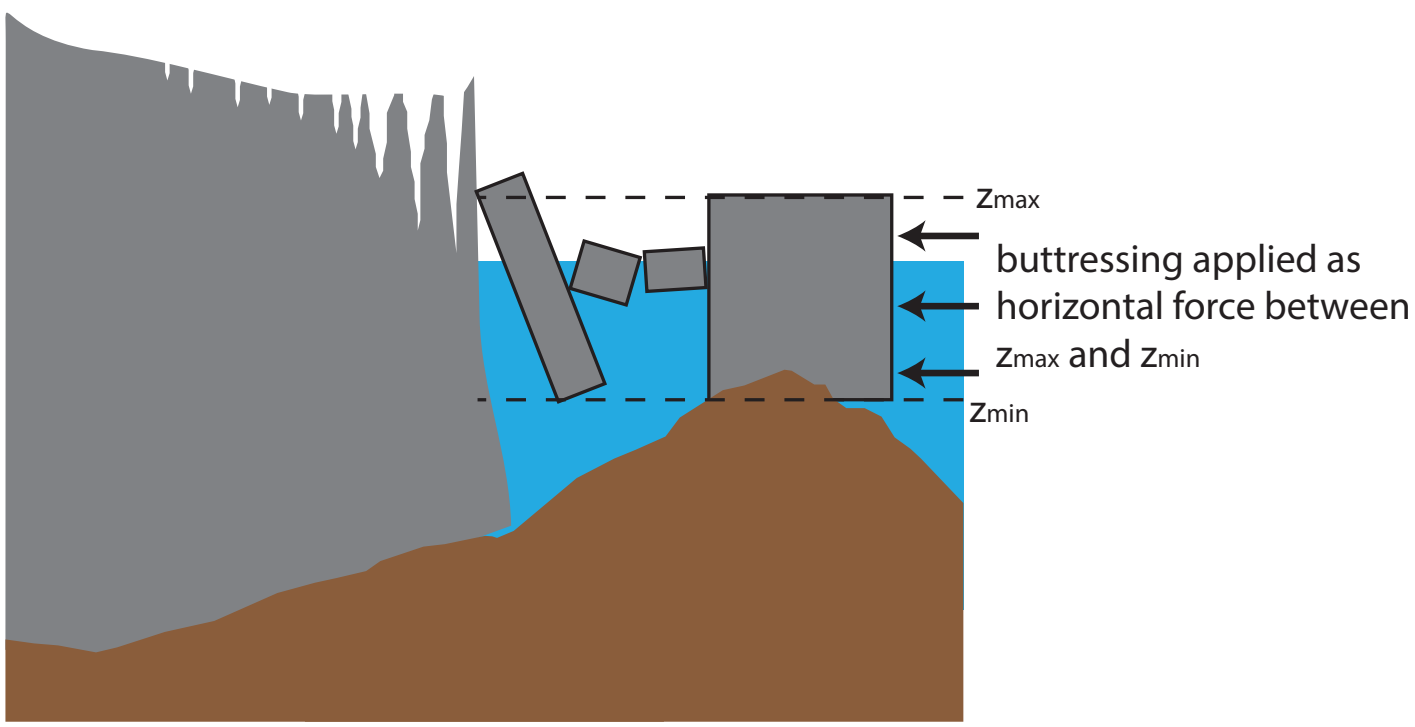

B. Slow buttressing removal from an ice shelf

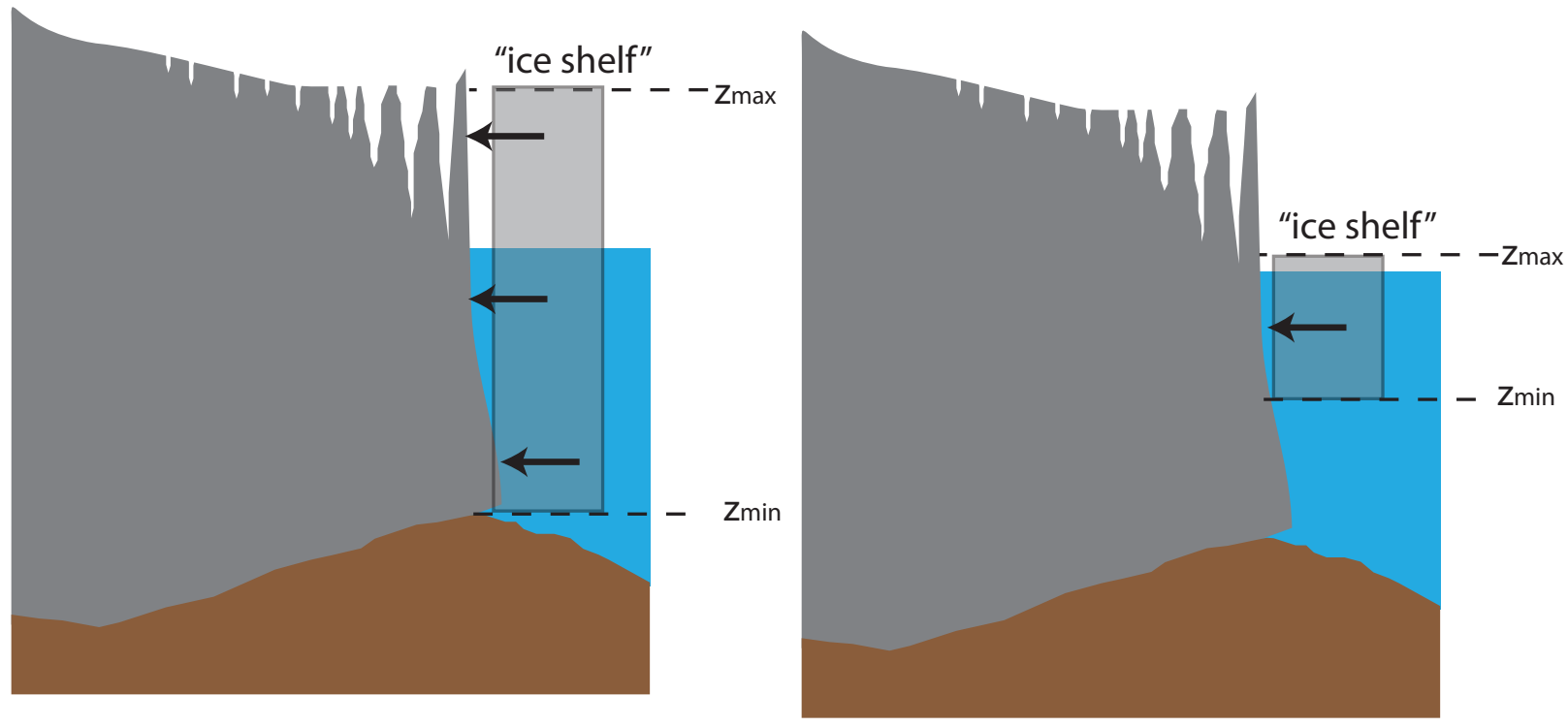

Fig. S8. Schematic illustrating the two scenarios where we apply buttressing. Panel A illustrates the scenario we envision in Fig 2 where buttressing results from a collection of icebergs with restraining forces originating from pinning points or force chains. Buttressing is applied as a constant horizontal force applied between $z_{\max }$ and $z_{\text {min }}$. Sudden removal of buttressing corresponds to rapid mélange blowout. Panel B illustrates gradual buttressing removal associated with a thinning or weakening ice shelf that gradually exposes the calving face. In this case, buttressing is applied initially as a horizontal force over the entire cliff face. Both the magnitude and depth range over which the buttressing is applied are gradually decreased to zero over a time interval $\Delta t$. 
A. weak serac filled ice

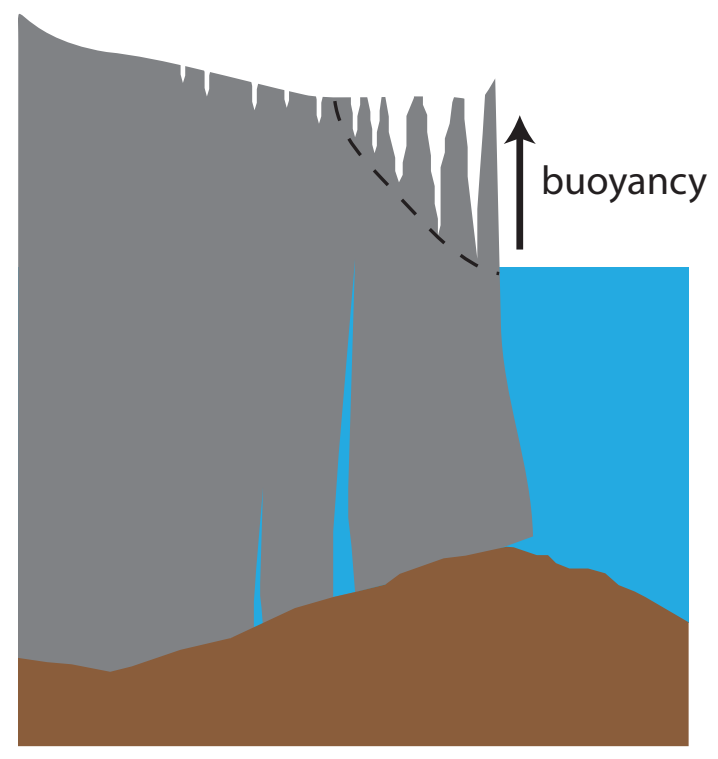

B. slump



Fig. S9. Sketch illustrating two modes of buoyant calving. In panel A, the ice near the calving front is perforated with seracs. Densely spaced seracs reduce the average density of ice resulting in an upward buoyancy force. Panel B illustrates a slump near the calving front, which could arise from shear localizing or progressive toppling over of seracs. This geometry also results in a buoyancy force. The continuum model $\mathrm{m}$-ice cannot resolve seracs and instead represents densely spaced surface crevasses as weaker failed ice, resulting in a calving cliff configuration that resembles panel $\mathrm{B}$. 
Time: 0a 49d 23hr
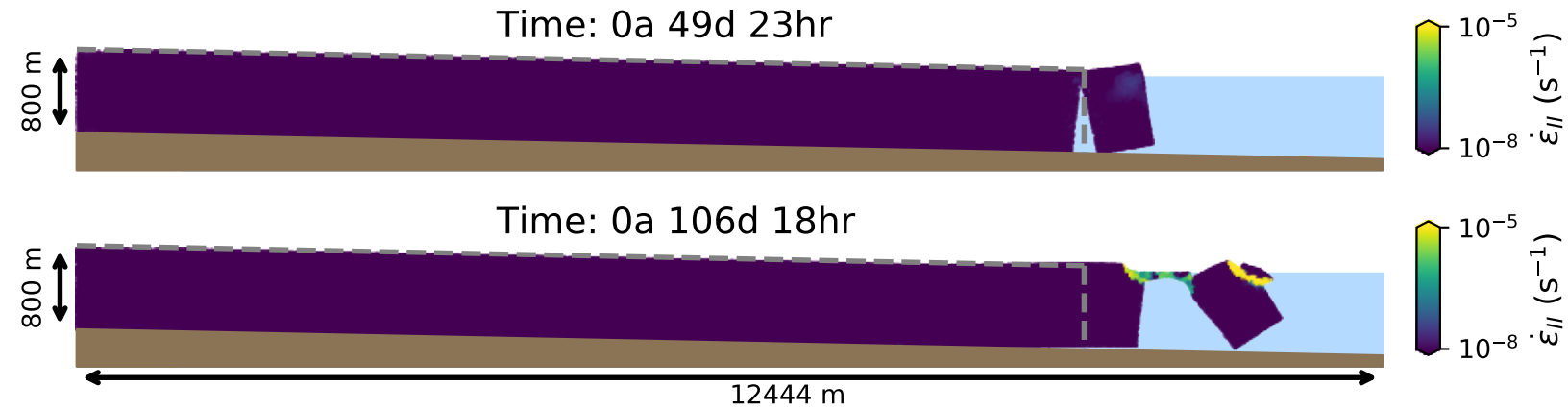

Fig. S10. Two snapshots illustrating super-buoyancy calving with a manually introduced basal crevasse. Dashed grey lines show the initial condition. The simulation was initialized with the calving front grounded $10 \mathrm{~m}$ below buoyancy. This mode of calving generates large calving cliff uplift and is favorable on a prograde bed with a glacier grounded close to or beneath buoyancy. 
Table S1. Parameters used in $\mathrm{m}$-ice simulations

\begin{tabular}{|c|c|c|c|}
\hline Parameter name & Symbol & Value & Unit \\
\hline Yield strength & $\tau_{y 0}$ & 0.75 & $\mathrm{MPa}$ \\
\hline Critical strain & $\epsilon_{\text {crit }}$ & 0.1 & \\
\hline Minimum yield strength & $\tau_{\min }$ & $10-25$ & $\mathrm{kPa}$ \\
\hline $\begin{array}{l}\text { Dislocation creep coeff } \\
\left(-20^{\circ} \mathrm{C},-15^{\circ} \mathrm{C},-10^{\circ} \mathrm{C},-5^{\circ} \mathrm{C}\right)\end{array}$ & $B_{\text {disl }}$ & $6.44,5.36,4.49,3.24$ & $10^{5} \mathrm{~Pa} \cdot \mathrm{a}^{1 / 3}$ \\
\hline $\begin{array}{l}\text { Dislocation creep coeff } \\
\left(-20^{\circ} \mathrm{C},-15^{\circ} \mathrm{C},-10^{\circ} \mathrm{C},-5^{\circ} \mathrm{C}\right)\end{array}$ & $B_{\text {disl }}$ & $\begin{array}{c}4.77,2.762,1.63 \\
0.984\end{array}$ & $10^{8} \mathrm{~Pa} \cdot \mathrm{a}$ \\
\hline Grain size & d & $1-10$ & $\mathrm{Mm}$ \\
\hline Friction coefficient & C & $4 \times 10^{6}$ & $\mathrm{~Pa}(\mathrm{~s} / \mathrm{m})^{1 / 3}$ \\
\hline Density of ice & $\rho_{i}$ & 910 & $\mathrm{~kg} / \mathrm{m}^{3}$ \\
\hline Density of water & $\rho_{w}$ & 1020 & $\mathrm{~kg} / \mathrm{m}^{3}$ \\
\hline Reference bed slope & $d b / d x$ & 0 & - \\
\hline $\begin{array}{l}\text { Reference initial surface } \\
\text { slope }\end{array}$ & $d s / d x$ & -0.02 & - \\
\hline
\end{tabular}


Table S2. Parameters used in DEM simulations

\begin{tabular}{|l|c|c|}
\hline Parameter name & DEM 1 & DEM 2 \\
\hline Cohesion & $0.02 \mathrm{MPA}$ & $0.04 \mathrm{MPa}$ \\
\hline Coefficient of friction & 0.1 & 0.1 \\
\hline Young's Modulus & $1 \mathrm{GPa}$ & $1 \mathrm{GPa}$ \\
\hline Poisson's ratio & 0.33 & 0.33 \\
\hline Calibrated compressive strength & $1.5 \mathrm{MPa}$ & $3 \mathrm{MPa}$ \\
\hline Calibrated Young's modulus & $4.6 \mathrm{GPa}$ & $4.5 \mathrm{GPa}$ \\
\hline Density of ice & $\rho_{i}$ & 910 \\
\hline Density of water & $\rho_{w}$ & 1020 \\
\hline
\end{tabular}




\section{Movie S1.}

Animation showing the evolution of a dry ice cliff $135 \mathrm{~m}$ tall. The top panel shows the accumulated plastic strain $\epsilon_{p}$, while the bottom panel shows the effective strain rate $\epsilon_{e}$. Calving initiates as a slump. The sloped calving front is stable to further calving and the glacier thins and advances with episodic avalanches from the cliff top. The frame rate increases in the later part of the simulation to illustrate stable cliff advance after the initial slump.

\section{Movie S2.}

Animation showing the evolution of a $400 \mathrm{~m}$ tall ice cliff grounded in $290 \mathrm{~m}$ water depth. The top panel shows the accumulated plastic strain $\epsilon_{p}$, while the bottom panel shows the effective strain rate $\epsilon_{e}$. The icebergs and calved debris is quickly transported away, exposing thicker ice upstream and triggering catastrophic collapse.

\section{Movie S3.}

Animation showing the evolution of a $800 \mathrm{~m}$ tall ice cliff grounded in $\sim 690 \mathrm{~m}$ water depth. The top panel shows the accumulated plastic strain $\epsilon_{p}$, while the bottom panel shows the effective strain rate $\epsilon_{e}$. A subaerial slump, triggers a buoyant calving event. Continued erosion of material from the calving cliff eventually triggers another calving front resulting in a cycle of quasimonthly calving events.

\section{Movie S4.}

Discrete element model (DEM) simulation showing a $70 \mathrm{~m}$ tall dry calving front with calibrated macroscopic compressive strength of ice $1.5 \mathrm{MPa}$ (parameters from DEM1, Table S2). The simulation results in a stable slumped calving front similar to that produced by $\mathrm{m}$-ice.

\section{Movie S5.}

Discrete element model (DEM) simulation showing a $135 \mathrm{~m}$ tall dry calving front with calibrated macroscopic compressive strength of ice $3 \mathrm{MPa}$ (parameters from DEM2, Table S2). The simulation results in a stable slumped calving front similar to that produced by $\mathrm{m}$-ice. 